\title{
Estabilidade físico-química e mercado do mexilhão (Perna perna) cultivado em Ubatuba - SP
}

Physicochemical stability and market of mussels (Perna perna) cultivated in Ubatuba - SP, Brasil

\author{
Érika Fabiane FURLAN ${ }^{*}$, Juliana Antunes GALVÃO ${ }^{1}$, Eduardo Oliveira SALÁN ${ }^{1}$, \\ Viviane Angeli YOKOYAMA ${ }^{1}$, Marília OETTERER ${ }^{1}$
}

\begin{abstract}
Resumo
O presente estudo objetivou caracterizar o mexilhão Perna perna como alimento no que se refere à estabilidade físico-química, valor nutricional e consumo. Os mexilhões avaliados foram coletados em três regiões distintas do litoral norte de São Paulo: praia da Barra Seca, praia do Engenho da Almada e costão do Cedro. Determinou-se a composição centesimal (umidade, proteína bruta, carboidrato, lipídios e cinza), o valor calórico, o pH e as bases voláteis nitrogenadas totais. Paralelamente foi realizado estudo de mercado, através de questionários não estruturados, aplicados aos comerciantes e consumidores locais. Detectou-se variação dos constituintes químicos dos mexilhões em função da sazonalidade, bem como, do local de origem destes. Estes constituem uma fonte protéica $\left(9,1 \mathrm{~g} .100 \mathrm{~g} \mathrm{~g}^{-1}\right)$, com baixo teor lipídico $\left(1,1 \mathrm{~g} .100 \mathrm{~g}{ }^{-1}\right)$ e calórico $\left(72,7 \mathrm{Kcal} .100 \mathrm{~g}^{-1}\right)$. Apresentaram uma estabilidade físico-química de 4 dias, sob temperatura de $10{ }^{\circ} \mathrm{C}(\mathrm{p} 1)$, conforme aferido pelos resultados apresentados, que não se correlacionaram entre si. No geral, os estabelecimentos comerciais apontaram uma preferência pela aquisição do mexilhão sem as conchas e uma maior demanda do produto preparado na forma de vinagrete. Foi diagnosticado o desconhecimento do produto pelos consumidores e conseqüente necessidade de marketing visando sua promoção.

Palavras-chave: frescor; composição centesimal; consumo.
\end{abstract}

\begin{abstract}
This research work consisted of characterizing Perna perna mussel as a food in terms of its physicochemical stability, nutritional value and consumption. Specimens of the mussel were collected from three sites off the northern coast of the state of São Paulo, namely Barra Seca, Engenho da Almada and Costão do Cedro. The centesimal composition (humidity, crude protein, carbohydrates, lipids and ash), caloric value, $\mathrm{pH}$ and total basic volatile nitrogen were determined. A market study was also carried out based on a nonstructured questionnaire distributed to local tradesmen and consumers. The chemical constituents of the mussels were found to vary according to the season and their site of origin. These mussels are a source of protein $\left(9.1 \mathrm{~g} .100 \mathrm{~g}^{-1}\right)$ with a low lipid $\left(1.1 \mathrm{~g} .100 \mathrm{~g}^{-1}\right)$ and calorie content $\left(72.7 \mathrm{Kcal} .100 \mathrm{~g}{ }^{-1}\right)$. The specimens displayed physicochemical stability for 4 days at a temperature of $10^{\circ} \mathrm{C}(\mathrm{pl})$, as evidenced by the physical and chemical results, which were noncorrelated. In general, businesses prefer to purchase shucked mussels and there was a higher demand for the product in the form of vinaigrette sauce. The consumer evinced unfamiliarity with the product, indicating the need for marketing efforts to promote it.

Keywords: freshness; nutrient composition; consumption.
\end{abstract}

\section{Introdução}

Grande parte da comercialização de moluscos bivalves é realizada na forma viva. No seu estado fresco, o mexilhão é exportado para os países da Europa.

O frescor é uma propriedade do pescado que exerce considerável influência sobre a sua qualidade, talvez seja o mais importante critério individual para julgar a qualidade da maioria dos produtos pesqueiros ${ }^{30}$.

No Brasil, os padrões de qualidade do pescado e derivados estão baseados na análise de compostos como bases nitrogenadas voláteis totais (N-BVT) e trimetilamina (TMA), bem como na mensuração do pH. Para a determinação das N-BVT, emprega-se um método relativamente simples e, conseqüentemente, largamente utilizado para avaliar quimicamente o frescor de um alimento marinho ${ }^{10,2}$.

Segundo ROSA et al. ${ }^{31}$, o mexilhão é considerado uma iguaria, não fazendo parte do cardápio diário da população,

Recebido para publicação em 4/7/2006

Aceito para publicação em 18/7/2007 (001786)

Departamento de Agroindústria, Alimentos e Nutrição

Escola Superior de Agricultura "Luiz de Queiroz" - ESALQ,

Universidade de São Paulo - USP,

Av. Pádua Dias, 11, CP 9, CEP 13418-900, Piracicaba - SP, Brasil,

E-mail: effurlan@pesca.sp.gov.br

* A quem a correspondência deve ser enviada e sua aceitação restringe-se a uma camada reduzida de consumidores.

WESTLUND ${ }^{35}$ aponta o crescimento populacional e econômico, a disponibilidade de renda e os fatores sociais, como fatores que podem contribuir com a futura demanda de produtos pesqueiros.

Para BATALHA et al. ${ }^{7}$, a eficácia de uma cadeia agroindustrial está ligada à sua capacidade de fornecer produtos e serviços adaptados às necessidades dos consumidores e BARNI et al. ${ }^{6}$ sugerem que a comercialização não se constitui em identificar nichos específicos do mercado, mas sim atender à evolução e às necessidades desse mercado e seus diferentes componentes.

Esta pesquisa objetivou determinar as características nutricionais, de mercado e a estabilidade físico-química dos mexilhões (Perna perna) cultivados e comercializados in natura no município de Ubatuba - SP, utilizando para este último os padrões estabelecidos pela legislação brasileira vigente para pescado ${ }^{11}$.

\section{Material e métodos}

\subsection{Coleta e preparo das amostras}

Cerca de $10 \mathrm{Kg}$ de mexilhões, da espécie Perna perna, foram coletados, mensalmente, de três distintos pontos de 
cultivo, no período de janeiro a março de 2003. Estes foram submetidos ao processo de desdobre, no qual o produtor faz a retirada dos mexilhões de cultivo dos cachos, separandoos da fauna acompanhante e retirando cracas e parasitas. Posteriormente, foram lavados com água do mar, no caso dos mexilhões provenientes do cultivo da praia do Engenho e com água tratada pela Secretaria de Energia, Recursos Hídricos e Saneamento (SABESP), nos outros dois cultivos (Barra Seca e costão do Cedro), efetuando assim a limpeza superficial das valvas. Depois deste processo, os mexilhões foram acondicionados em sacos de ráfia e transportados em recipiente isotérmico contendo gelo comercial filtrado, na proporção de 3:1 (mexilhão/gelo), sem contato direto entre estes, evitando-se assim a morte dos bivalves. Chegando ao setor de Processamento de Alimentos do Departamento de Agroindústria, Alimentos e Nutrição da Escola Superior de Agricultura Luiz de Queiroz, Universidade de São Paulo, as amostras foram armazenadas a granel, em refrigerador vertical doméstico, em temperatura média de $10{ }^{\circ} \mathrm{C} \mathrm{p} 1{ }^{\circ} \mathrm{C}$, até o momento das análises. Todas as análises foram realizadas em triplicatas. As determinações de pH e de N-BVT nos mexilhões tiveram início 24 horas após a coleta das amostras e seguiram dia-a-dia, até que os resultados atingissem o limite para N-BVT estipulado pela legislação vigente, de $30 \mathrm{mg} \mathrm{N} .100 \mathrm{~g}^{-1}$ de pescado ${ }^{11}$.

\subsection{Composição centesimal}

As amostragens para esta determinação seguiram a mesma forma acima descrita, mas o período se estendeu de novembro de 2002 a março de 2003.

Excetuando-se a determinação de carboidratos, que ocorreu por diferença, (fração NIFEXT), as demais análises (umidade, proteína bruta, lipídios e cinza) seguiram de acordo com HUNGERFORD ${ }^{16}$. A umidade, através do método gravimétrico, em estufa a $105^{\circ} \mathrm{C}$ até peso constante. O teor de proteína bruta, pelo método de Kjeldahl e conversão em proteína multiplicando o valor obtido pelo fator 6,25 . Os lipídios foram determinados por extração com hexano, pelo método de Soxhlet e o teor de cinza pelo método gravimétrico, com incineração da matéria orgânica em bico de Bunsen, seguido de calcinação em mufla a $550{ }^{\circ} \mathrm{C}$.

\subsection{Valor calórico}

Determinado segundo LATHAM (2002), multiplicando-se o teor lipídico por 9 e os teores de proteína e de carboidrato por 4. Sendo expresso em Kcal.

\subsection{Bases nitrogenadas voláteis totais (N-BVT)}

Determinação pelo método adotado pelo IFOP - Instituto de Fomento Pesqueiro do Chile, descrito por MORGA ${ }^{26}$. Adicionouse, a 50 g do músculo e líquido intravalvar homogeneizados em liquidificador, $150 \mathrm{~mL}$ de TCA 5\%; homogeneizou-se por 1 minuto; deixando-se em repouso por 15 minutos. Depois deste período, filtrou-se em papel filtro, ajustando-se o volume a $250 \mathrm{~mL}$ em balão volumétrico, lavando-se o filtro com água destilada. Em um balão de destilação adicionaram-se $20 \mathrm{~mL}$ do filtrado, $150 \mathrm{~mL}$ de água destilada e $2 \mathrm{~g}$ de MgO; o balão foi fechado e submetido ao aquecimento. O destilado foi recebido em erlenmeyer contendo $20 \mathrm{~mL}$ de ácido bórico a $1 \%$ com indicador misto (vermelho de metila e verde de bromocresol); destilaram-se aproximadamente $150 \mathrm{~mL}$ e procedeu-se à titulação com $\mathrm{HCl}$ 0,02 N, até viragem da cor azul para rosa. O cálculo da quantidade de Nitrogênio volátil/100 gramas da amostra foi obtido pela fórmula:

mg de $\mathrm{N}$ volátil/ $100 \mathrm{~g}$ de pescado $=\frac{\mathrm{G} \times \mathrm{N} \times 14}{\mathrm{P}} 100$ onde:

$\mathrm{G}=$ volume de $\mathrm{HCl} \mathrm{0,02} \mathrm{N}$ gasto;

$\mathrm{N}=$ normalidade do $\mathrm{HCl}$;

$\mathrm{P}=$ peso do pescado na alíquota destilada (4 g).

\section{$2.5 \mathrm{pH}$}

Determinado por leitura em potenciômetro Digimed modelo DMPH1, tendo utilizado $50 \mathrm{~g}$ da amostra homogeneizada com $10 \mathrm{~mL}$ de água destilada ${ }^{12}$.

\subsection{Análise estatística}

Os constituintes químicos foram analisados pelo programa estatístico SANEST, utilizando-se da análise de variação de classes múltiplas balanceadas, ao acaso, e submetidas a teste de variância e de Tukey. Todos os dados aqui levantados foram correlacionados utilizando-se do pacote estatístico SAS (Versão 802).

\subsection{Avaliação do consumo}

Visando conhecer o perfil dos consumidores de moluscos da estância balneária de Ubatuba, seus hábitos de consumo e preferências, bem como as principais formas de aquisição do produto, o comportamento geral dos fornecedores, entre outros dados pertinentes, foram realizadas entrevistas pessoais, empregando-se questionário não estruturado, com os comerciantes de 31 pontos de venda da Estância Balneária de Ubatuba, SP, sendo 14 restaurantes e 17 quiosques. Quanto aos consumidores, estes também foram entrevistados pessoalmente através de questionário não estruturado, que foram aplicados em locais de fluxo de venda (supermercados).

O tamanho da amostra foi definido conforme discutido por MATTAR $^{24}$ e BARBETA ${ }^{5}$, para uma população desconhecida, com nível de significância de $99 \%$ e erro amostral de $1 \%$. Isto é, estes critérios determinam que, de 100 levantamentos semelhantes ao planejamento, em 99 deles as médias obtidas pela amostra estariam contidas nos intervalos numéricos previstos para a sua extrapolação em relação ao universo, determinados pela margem de erro de $1 \%$.

Os dados obtidos foram tabulados, codificados e correlacionados utilizando-se do pacote estatístico SAS (Versão 802).

\section{Resultados e discussão}

\subsection{Composição centesimal}

Os valores médios para umidade encontrados nesta pesquisa, 84,19 g. $100 \mathrm{~g}^{-1}, 83,16 \mathrm{~g} .100 \mathrm{~g}^{-1}$ e $83,94 \mathrm{~g} .100 \mathrm{~g}^{-1}$ para 
os mexilhões cultivados nas praias do Engenho e da Barra Seca e no costão do Cedro, respectivamente, apresentaram-se superiores aos encontrados por TAVARES et al. ${ }^{33}$, da ordem de 72,12 g. $100 \mathrm{~g}^{-1}$ para a mesma espécie. No entanto, esta diferença pode ser explicada pelas distintas metodologias utilizadas no processo de desconchamento dos mexilhões, nas quais os autores supra citados lançaram mão de uma pré-cocção para promover a abertura das valvas e na presente pesquisa estes foram abertos ainda vivos, cortando-se o músculo adutor.

Na base de dados de nutrientes do Departamento de Agricultura dos Estados Unidos (USDA), encontra-se que o mexi-

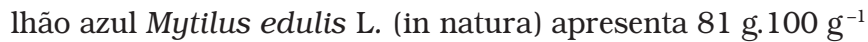
de umidade e $61 \mathrm{~g} .100 \mathrm{~g}^{-1}$ após cocção ${ }^{8}$. Confirmando-se assim que a variação no teor de umidade pode estar relacionada ao método de preparo e, no caso, a metodologia de obtenção da amostra. LIRA et al. ${ }^{19}$ explicam que durante o cozimento as proteínas se desnaturam, processo em que as proteínas solúveis tornam-se insolúveis e perdem parte da umidade. Por isto a carne crua contém mais água que a cozida.

No mês de dezembro, detectou-se um maior teor médio de umidade (Tabela 1), em concordância com GELLI ${ }^{14} \mathrm{e}$ MAGALHÃES ${ }^{22}$, mas contrariando os dados apresentados por TAVARES et al. ${ }^{33}$. No entanto, estes mesmos autores afirmaram que os teores de umidade apresentam uma relação inversa aos valores de lipídeos, fato também constatado nesta pesquisa.

No mês de dezembro, foi encontrada diferença significativa entre os teores de umidade dos mexilhões de todos os cultivos, nos níveis de 1 e $5 \%$ de significância. O teor de lipídeos foi significativamente menor nos mexilhões provenientes do cultivo do costão do Cedro.

O teor de umidade também apresentou correlação negativa com os teores de proteína e carboidratos. Para este último componente, esta relação já era esperada, visto o conteúdo hídrico representar a maior percentagem na constituição dos moluscos e o carboidrato ter sido mensurado como fração NIFEXT. No entanto, quando se considerou o local de cultivo, só houve correlação entre os teores de umidade e protéico para os mexilhões provenientes da praia do Engenho e, quanto aos teores de umidade e carboidratos, não houve correlação.

O menor teor de umidade no mês de novembro também foi diagnosticado por GELLI ${ }^{14}$ e MAGALHÃES ${ }^{22}$. Esta última autora, estudando machos e fêmeas, verificou que a percentagem de umidade não diferia entre os sexos. Entretanto, a autora constatou diferenças entre os estádios do ciclo reprodutivo em um mesmo sexo, afirmando que o decréscimo da quantidade de água dos tecidos, principalmente nas fêmeas, acompanha o aumento da atividade reprodutiva. Portanto, a determinação dos constituintes químicos é importante, não somente do ponto de vista nutricional, mas também ecológico.

Os mexilhões (Perna perna) apresentaram teores protéicos médios de 9,09 g. $100 \mathrm{~g}^{-1}$ em relação ao peso fresco, não havendo diferença significativa entre os mexilhões dos diferentes cultivos nos níveis de 1 e $5 \%$ de significância. TAVARES et al. ${ }^{33}$ encontraram valores superiores para proteína (próximos a 20 g. $100 \mathrm{~g}^{-1}$ ) e demais frações. Segundo MAGALHÂES ${ }^{22}$, os animais maduros apresentam teores protéicos ainda maiores.

Os valores protéicos encontrados neste trabalho estão de acordo com GELLI ${ }^{14}$ e MAGALHÃES ${ }^{22}$, que encontraram valores de 6,7 a 9,5 g. $100 \mathrm{~g}^{-1}$ e 9,68 g. $100 \mathrm{~g}^{-1}$, respectivamente. Sendo que, esta última autora citada, trabalhou com mexilhões depurados, ou seja, eliminou o conteúdo intestinal, evitando possível interferência na avaliação do teor protéico destes animais.

O menor conteúdo protéico $\left(6,31\right.$ g.100 $\left.\mathrm{g}^{-1}\right)$ refere-se à amostragem do costão do Cedro no mês de janeiro, período em que todas as amostras apresentaram menor porcentagem de proteína (praia do Engenho 6,98 g. $100 \mathrm{~g}^{-1}$ e da Barra Seca $7,44 \mathrm{~g} .100 \mathrm{~g}^{-1}$ ), mas estes valores não diferiram estatisticamente, ao nível de $1 \%$ de significância.

De acordo com MAGALHÃES ${ }^{22}$, são grandes as dificuldades para se comparar resultados de teor protéico, mesmo entre animais da mesma espécie, justificadas pelas distintas regiões de coleta destes animais, os diferentes estádios do ciclo reprodutivo, bem como as diversas metodologias utilizadas para a determinação deste componente. Esta pesquisa vem confirmar a existência da variação do teor protéico em função dos locais de origem destes organismos, bem como a existência de uma correlação positiva alta entre os teores de proteína e lipídeos.

O teor lipídico não sofreu grandes oscilações ao longo desta pesquisa. O maior (1,66 g. $\left.100 \mathrm{~g}^{-1}\right)$ está relacionado aos mexilhões cultivados na praia do Engenho da Almada e o menor $\left(0,61\right.$ g. $\left.100 \mathrm{~g}^{-1}\right)$ ao costão do Cedro, referentes aos meses de novembro e dezembro (Tabela 1). Os mexilhões coletados na Barra Seca apresentaram um teor lipídico constante, diferindo, estatisticamente, apenas no mês de fevereiro quando este se reduziu a $1,08 \mathrm{~g} .100 \mathrm{~g}^{-1}$.

Tabela 1. Média da composição centesimal e valor calórico dos mexilhões cultivados em Ubatuba - SP, no período de novembro de 2002 a março de 2003.

\begin{tabular}{|c|c|c|c|c|c|c|}
\hline \multirow[t]{2}{*}{ Meses } & Umidade & Proteína & Lipídeos & Cinza & Carboidrato & \multirow[t]{2}{*}{ Calorias (Kcal.100 $\mathrm{g}^{-1}$ ) } \\
\hline & \multicolumn{5}{|c|}{$\left(\mathrm{g} .100 \mathrm{~g}^{-1}\right)$} & \\
\hline Novembro & $81,41^{\mathrm{c}}$ & $10,73^{a}$ & $1,49^{\mathrm{a}}$ & $1,58^{\mathrm{d}}$ & $4,85^{\mathrm{b}}$ & 75,69 \\
\hline Dezembro & $85,37^{\mathrm{a}}$ & $8,94^{\mathrm{b}}$ & $1,06^{\mathrm{c}}$ & $1,68^{\mathrm{c}}$ & $2,95^{\mathrm{c}}$ & 57,10 \\
\hline Janeiro & $83,45^{\mathrm{b}}$ & $6,91^{\mathrm{c}}$ & $0,99^{c}$ & $1,43^{e}$ & $7,22^{\mathrm{a}}$ & 65,43 \\
\hline Fevereiro & $84,96^{\mathrm{a}}$ & $9,28^{\mathrm{b}}$ & $1,00^{\mathrm{c}}$ & $2,00^{\mathrm{b}}$ & $2,76^{\mathrm{c}}$ & 53,36 \\
\hline Março & $83,65^{b}$ & $9,6^{\mathrm{b}}$ & $1,16^{\mathrm{b}}$ & $2,25^{\mathrm{a}}$ & $3,34^{c}$ & 62,20 \\
\hline Desvio padrão & 2,07 & 1,56 & 0,23 & 0,26 & 1,86 & 8,59 \\
\hline
\end{tabular}

*Médias seguidas da mesma letra não diferem entre si ao nível de $5 \%$ de probabilidade. 
Segundo ACKMAN ${ }^{1}$, o conteúdo lipídico de mariscos pode estar no intervalo de 1 a 2 g. $100 \mathrm{~g}^{-1}$ e, uma razão básica apontada pelo autor para este reduzido conteúdo em lipídeos, é que os bivalves armazenam seus excedentes ou reservas de energia na forma de glicogênio e não como gordura. Constatou-se, no presente estudo, que os mexilhões Perna perna apresentam maior quantidade de carboidrato que lipídeos (Tabela 1) e que os teores de carboidrato encontrados para este mexilhão superam os valores encontrados para outros moluscos como Mytella falcata (1,03 g.100 g ${ }^{-1}$ ), Anomalocardia brasiliana (2,39 g. $\left.100 \mathrm{~g}^{-1}\right)$ e Tagelus plebeus $\left(2,35 \mathrm{~g} .100 \mathrm{~g}^{-1}\right)$ estudados por LIRA et al. ${ }^{19}$.

A média geral encontrada para o componente cinza foi 1,79 g. $100 \mathrm{~g}^{-1}$. Verificou-se que este componente também não sofreu grandes oscilações.

A quantidade de cinza apresentou correlação negativa com os valores para carboidrato, mas considerando o fator praias, ou seja, o local de origem dos organismos, esta correlação não é clara.

Os moluscos apresentam em sua carne maior teor de carboidrato e menor de nitrogênio total, quando comparados aos peixes e crustáceos. Segundo JAY ${ }^{17}$ e LOMOVASKY, MALANGA e CALVO ${ }^{21}$, os carboidratos são encontrados, principalmente na forma de glicogênio. Nesta pesquisa, como apresentado na Tabela 1, o maior valor médio para carboidrato foi encontrado em janeiro e os menores em dezembro, fevereiro e março. Discordando, em parte, dos resultados de GELLI ${ }^{14}$, que notificou valores mínimos para este constituinte de dezembro a fevereiro. No entanto, pode-se observar que a menor média no mês de dezembro representa o teor mínimo de carboidrato detectado para as amostras do costão do Cedro ( 1,31 g. $\left.100 \mathrm{~g}^{-1}\right)$, pois os mexilhões provenientes da praia do Engenho e da Barra Seca acusaram teores mínimos em fevereiro $\left(2,67 \mathrm{~g} .100 \mathrm{~g}^{-1} \mathrm{e}\right.$ 2,71 g. $100 \mathrm{~g} \mathrm{~g}^{-1}$, respectivamente). Excetuando-se as amostras de dezembro do costão do Cedro e da praia do Engenho, em janeiro, não houve diferença significativa no teor de carboidrato dos mexilhões coletados entre as distintas praias.

Segundo SCHRAMM ${ }^{32}$, há flutuação sazonal no conteúdo deste componente em função do ciclo reprodutivo do mexilhão. O conteúdo de carboidratos, significativamente superior no mês de janeiro, pode estar associado à eliminação de gametas, visto que MARQUES ${ }^{23}$ afirma que este período do verão caracterizase como o pico da reprodução destes organismos.

De acordo com MAGALHÃES ${ }^{22}$, nos bivalves são freqüentes as variações nos teores de carboidrato e lipídeos e, menos comum nos de proteínas, que se correlacionam, diretamente, com a atividade reprodutiva.

De acordo com os dados obtidos no presente trabalho, o valor calórico médio de uma porção equivalente a $100 \mathrm{~g}$ do produto fresco é de cerca de 62,76 Kcal. Estes valores apresentaram-se consistentes, visto que o pico $(75,69 \mathrm{Kcal})$ coincidiu com o período de engorda destes organismos (Tabela1).

Levando-se em consideração os constituintes químicos, aqui analisados, pode-se constatar que o mexilhão é uma fonte protéica de reduzido conteúdo lipídico e calórico, ou seja, um alimento conveniente para o padrão de vida atual, que devido à tendência sedentária, exige uma menor ingestão calórica diária.

\subsection{N-BVT}

O pescado pode ser alterado por ação enzimática e bacteriana com produção de vários compostos nitrogenados. A mensuração destes compostos se dá pela determinação das bases voláteis que aumentam em função da deterioração do produto.

Os valores médios encontrados neste trabalho para N-BVT, 24 horas após as coletas dos mexilhões, estão em conformidade com a legislação, uma vez que o limite legal adotado em muitos países como Japão, Austrália, Argentina, Alemanha, incluindo o Brasil, é de $30 \mathrm{mg}$ de N.100 g ${ }^{-1}$ de carne. Estes valores correspondentes à qualidade do produto 24 horas após a coleta, são de suma importância para os produtores e consumidores locais, visto que o produto não é (e não deve ser) comercializado fora deste período (Tabela 2). Os produtores costumam, na maioria das vezes, retorná-lo ao ambiente marinho quando não comercializado em 24 horas; apenas alguns congelam o produto após este período.

Levando-se em conta os limites críticos estipulados para N-BVT pela legislação brasileira e os resultados apresentados

Tabela 2. N-BVT (mg.100 $\mathrm{g}^{-1}$ ) nos mexilhões, mantidos sob refrigeração, de 24 a 192 horas após as coletas.

\begin{tabular}{|c|c|c|c|c|c|c|c|c|}
\hline & 24 & 48 & 72 & 96 & 120 & 144 & 168 & 192 \\
\hline & \multicolumn{8}{|c|}{ Horas } \\
\hline \multicolumn{9}{|l|}{ Janeiro } \\
\hline Engenho & 8,9 р 0,4 & 12 p 0,5 & 13,6 p 0,5 & 13,1 p 0,4 & 14 p 0,0 & 19,9 p 1,1 & 38 p 0,5 & 59,5 p 0,0 \\
\hline Barra Seca & 7,5 р 0,4 & $12,1 \mathrm{p} 0,5$ & 13,1 p 1,1 & 11,7 p 0,8 & 13 p 0,5 & 17,9 р 0,5 & 20,1 р 0,4 & 22,5 p 0,2 \\
\hline Cedro & 8,9 р 0,8 & 11,9 p 0,0 & 13,1 p 0,4 & 27,8 р 0,4 & 34,4 p 1,1 & 37,8 p 0,0 & 60,1 p 0,5 & 82,6 p 1,0 \\
\hline \multicolumn{9}{|l|}{ Fevereiro } \\
\hline Engenho & 7,2 p 0,4 & 8,4 p 0,0 & 7,7 p 0,0 & 7 p 0,0 & 12,6 p 0,0 & $19,8 p 1,3$ & - & - \\
\hline Barra Seca & 6,3 p 0,0 & 7,5 p 1,1 & 4,9 p 0,0 & 5,4 p 0,4 & 10,7 p 0,4 & 8,8 p 0,3 & 14,4 p 0,5 & 38,2 p 0,0 \\
\hline Cedro & 8,2 p 0,4 & 8,4 p 0,7 & 4,9 p 0,0 & 6,5 p 0,4 & 10,5 p 0,7 & 7,6 p 1,2 & 23,8 p 0,0 & 28,4 p 0,7 \\
\hline \multicolumn{9}{|l|}{ Março } \\
\hline Engenho & 5,4 p 1,8 & 12,4 p 0,4 & 9,8 р 0,7 & 9,8 p 0,0 & 17,7 p 0,8 & 16,6 p 0,4 & 7,7 р 0,7 & 14,9 р 0,4 \\
\hline Barra Seca & 6,1 p 0,4 & 9,1 p 0,0 & 14,2 p 0,4 & 11 p 0,4 & 17,5 p 0,0 & 19,8 p 0,4 & 28,7 p 1,2 & 29,3 р 0,7 \\
\hline Cedro & 7 p 0,0 & 10,7 p 0,4 & 12,4 p 0,4 & 14,5 p 0,4 & 16,6 p 0,4 & 20,3 р 0,7 & 17 p 0,4 & 20,3 p 0,7 \\
\hline
\end{tabular}


na Tabela 2, pode-se assegurar uma estabilidade de 6 a 7 dias para os mexilhões Perna perna in natura, se mantidos à temperatura de $10{ }^{\circ} \mathrm{C}(\mathrm{pl})$; com exceção dos mexilhões coletados em janeiro no costão do Cedro que atingiram $30 \mathrm{mg}$ de N-BVT no quinto dia após a coleta. O manual on line Freshness, Quality and Safety in Seafoods ${ }^{13}$ indica uma vida útil para moluscos frescos, provenientes de águas quentes, de 8 a 12 dias sob temperatura de refrigeração $\left(0^{\circ} \mathrm{C}\right)$ e ANTONIOLLI ${ }^{3}$ preconizou vida útil de 7 dias para mexilhões cozidos e armazenados a $4{ }^{\circ} \mathrm{C} \mathrm{p} \square{ }^{\circ} \mathrm{C}$.

A maior velocidade de degradação dos mexilhões provenientes do costão do Cedro, no mês de janeiro, pode estar associada a um provável maior tempo de espera das amostras até o seu acondicionamento em gelo, ou seja, ao maior tempo de exposição destas à temperatura ambiente $\left(31,6^{\circ} \mathrm{C}\right)$. HUSS ${ }^{15}$ afirmou que a refrigeração adequada dos produtos pesqueiros é essencial para controle do crescimento de microorganismos, inclusive dos patogênicos.

MENDEZ ${ }^{25}$ comparando os índices de qualidade N-BVT e TMA afirmou que o comportamento linear do N-BVT é superior ao do TMA, indicando que ambos os índices são intercambiáveis, bastando apenas a determinação de N-BVT para os fins visados.

WAKSMAN e LOMANITZ ${ }^{34}$ verificaram que, se pouco ou nenhum carboidrato estiver presente, o conteúdo de amônia ou de bases voláteis aumenta apreciavelmente durante a deterioração da carne, porém, se carboidratos estiverem presentes, a decomposição protéica com formação de amônia fica deprimida. Portanto, considerando-se os níveis de carboidrato encontrados nos mexilhões, é possível um caminho diferenciado na deterioração deste molusco quando comparado a outros tipos de pescado marinho, como já sugerido por JAY ${ }^{17}$, indicando que padrões específicos para cada tipo de pescado devem ser definidos.

\section{$3.3 \mathrm{pH}$}

O processo de decomposição, quase sempre, altera a concentração de íons de hidrogênio de um alimento. A determinação do $\mathrm{pH}$ é importante no caso do pescado, pois este é de baixa acide $z^{11,33}$.
Os valores de $\mathrm{pH}$ encontrados neste trabalho variaram de 6,1 a 7,2, sendo as médias obtidas 24 horas após as coletas dos mexilhões dos cultivos do Engenho da Almada, Barra Seca e costão do Cedro 6,27; 6,3; e 6,24, (Tabela 3). Considerando-se o pH próximo à neutralidade como ótimo para o crescimento de bactérias patogênicas, extremo cuidado deve ser tomado com este produto, desde a coleta até a mesa do consumidor.

O RIISPOA - Regulamento de Inspeção Industrial e Sanitária de Produtos de Origem Animal - estabelece o limite de $\mathrm{pH}$ para carne externa de peixes inferior a 6,8 e para interna, inferior a 6,5, não contemplando, especificamente, os molus$\cos ^{11}$. Tomando-se estes valores como referência, as amostras provenientes do cultivo do costão do Cedro atingiram $\mathrm{pH}$ de 6,5 no quarto dia após as coletas dos meses de janeiro e março; enquanto, no mês de fevereiro, igual $\mathrm{pH}$ foi atingido apenas no sétimo dia de armazenamento. As amostras da praia do Engenho chegaram ao pH 6,5, sempre no quarto dia após as coletas. Enquanto as provenientes da Barra Seca, atingiram esse $\mathrm{pH}$ no quarto dia após a coleta de março, no sexto dia após a coleta de fevereiro e no sétimo dia de armazenamento de janeiro.

Cruzando-se estes dados obtidos para o $\mathrm{pH}$ dos mexilhões com os obtidos para N-BVT, não é possível estabelecer uma correlação. Muitos autores consideram que a determinação do pH não é um índice seguro do estado de frescor. Seu uso é geralmente restrito por variar de amostra para amostra e por ocorrerem flutuações durante o período de estocagem ${ }^{9,27,28}$, o que também foi observado nesta pesquisa.

ASHIE, SMITH e SIMPSON ${ }^{4}$ explicam que os bivalves estocam energia em seus tecidos na forma de glicogênio e que o ácido lático produzido, como resultado da glicogenólise, reduz o pH. LIUZZO et al..$^{20}$ e JAY ${ }^{17}$ constataram decréscimo uniforme e significativo do $\mathrm{pH}$ da carne de ostras e do seu líquido intravalvar com o período de estocagem em gelo. No presente estudo, constatou-se um aumento do $\mathrm{pH}$ da carne dos mexilhões durante o período de estocagem e, até mesmo, algumas flutuações neste período, diferente do apresentado pelos autores que trabalharam com ostras. OGAWA e MAIA ${ }^{28}$ comentam que os valores de ácido lático, em moluscos, são extremamente baixos devido à baixa atividade da L-lactatodesidrogenase. $\mathrm{Na}$ Tabela 3, é possível observar que o pH da carne dos mexilhões 24 horas após as coletas, dos três cultivos, mostrou-se uniforme

Tabela 3. Valores de $\mathrm{pH}$ da carne dos mexilhões in natura, mantidos sob refrigeração, de 24 a 192 horas após as coletas.

\begin{tabular}{|c|c|c|c|c|c|c|c|c|}
\hline & 24 & 48 & 72 & 96 & 120 & 144 & 168 & 192 \\
\hline & \multicolumn{8}{|c|}{ Horas } \\
\hline \multicolumn{9}{|l|}{ Janeiro } \\
\hline Engenho & 6,2 p 0,0 & 6,4 p 0,0 & 6,4 p 0,0 & 6,5 p 0,0 & 6,7 p 0,0 & 6,9 p 0,0 & 6,9 p 0,0 & 7,2 p 0,0 \\
\hline Barra Seca & 6,2 p 0,0 & 6,2 p 0,0 & $6,2 \mathrm{p} 0,0$ & 6,3 p 0,1 & 6,4 p 0,0 & 6,4 p 0,0 & 6,5 p 0,0 & 6,8 p 0,0 \\
\hline Cedro & 6,1 p 0,0 & 6,4 p 0,0 & 6,4 p 0,0 & 6,5 p 0,0 & 6,6 p 0,0 & 6,8 p 0,0 & 6,7 p 0,0 & 7,0 p 0,0 \\
\hline \multicolumn{9}{|l|}{ Fevereiro } \\
\hline Barra Seca & 6,4 p 0,0 & 6,3 p 0,0 & 6,3 p 0,0 & 6,4 p 0,0 & 6,4 p 0,0 & 6,5 p 0,0 & 6,5 p 0,0 & 6,6 p 0,0 \\
\hline Cedro & 6,4 p 0,0 & 6,3 p 0,0 & 6,3 p 0,0 & 6,4 p 0,0 & 6,4 p 0,0 & 6,4 p 0,0 & 6,5 p 0,0 & 6,5 p 0,0 \\
\hline \multicolumn{9}{|l|}{ Março } \\
\hline Engenho & 6,1 p 0,0 & 6,1 p 0,0 & 6,4 p 0,0 & 6,5 p 0,0 & 6,5 p 0,0 & 6,5 p 0,0 & 6,6 p 0,0 & 6,6 p 0,0 \\
\hline Barra Seca & 6,3 p 0,0 & 6,1 p 0,0 & 6,4 p 0,0 & 6,5 p 0,0 & 6,5 p 0,0 & 6,6 p 0,0 & 6,7 p 0,0 & 6,8 p 0,0 \\
\hline Cedro & 6,2 p 0,0 & 6,1 p 0,0 & $6,4 \mathrm{p} 0,0$ & 6,5 p 0,0 & 6,5 p 0,0 & 6,5 p 0,0 & 6,5 p 0,0 & 6,7 p 0,0 \\
\hline
\end{tabular}


dentro do mesmo período, ou seja, considerando-se apenas o $\mathrm{pH}$, os mexilhões apresentaram qualidade similar dentro do mesmo período de coleta.

\subsection{Avaliaçáo do consumo}

Para WIEFELS ${ }^{36}$, da mesma forma que no Brasil existe um imenso potencial de produção de pescado, mormente através do desenvolvimento da aqüicultura, também existe um enorme potencial de consumo. De forma geral, o pescado está sendo cada vez mais demandado no mundo por suas qualidades nutricionais.

A comercialização de mexilhões é praticada localmente (Ubatuba - SP) durante todo o ano, concentrando-se no verão, em função da presença dos turistas. Estes são os maiores consumidores, juntamente com os restaurantes e bares locais. A forma predominante de comercialização pelos mitilicultores é in natura ainda na concha (mariscado) e o preço é ditado pelo mercado consumidor ${ }^{29}$.

Para BARNI et al. ${ }^{6}$, historicamente, o pescado fresco tem no mercado consumidor uma acolhida mais favorável que o congelado ou que qualquer outra forma de conservação. No entanto, devido à sua natureza perecível, à limitada capacidade de armazenagem e às dificuldades envolvidas no transporte desse tipo de produto a longas distâncias, o produto congelado é preferido pelos atacadistas/distribuidores e varejistas, concordando com os resultados desta pesquisa para restaurantes, que têm demanda de mexilhões ao redor de 16 a $30 \mathrm{~kg} / \mathrm{mês}$ e apresentaram uma tendência em adquirir os mexilhões na forma congelada na sua maioria, vide Figura 1.

Os estabelecimentos que apresentaram a demanda superior a $30 \mathrm{~kg} / \mathrm{mês}$, além de comercializar o mexilhão na forma de diferentes pratos, têm $20 \%$ de sua comercialização sob a forma à vinagrete. Sendo, o mexilhão à vinagrete o prato mais comercializado, respondendo por $25,8 \%$ da demanda total, concordando com dados também relatados por BARNI et al. ${ }^{6}$, em pesquisa na qual os autores descrevem a forma de consumo de mexilhões por paulistanos, curitibanos e porto-alegrenses.

Os estabelecimentos de maior demanda compõem os $50 \%$ que preferem adquirir o produto fresco e, normalmente, pertencem a pessoas mais preocupadas quanto à divulgação dos produtos locais.

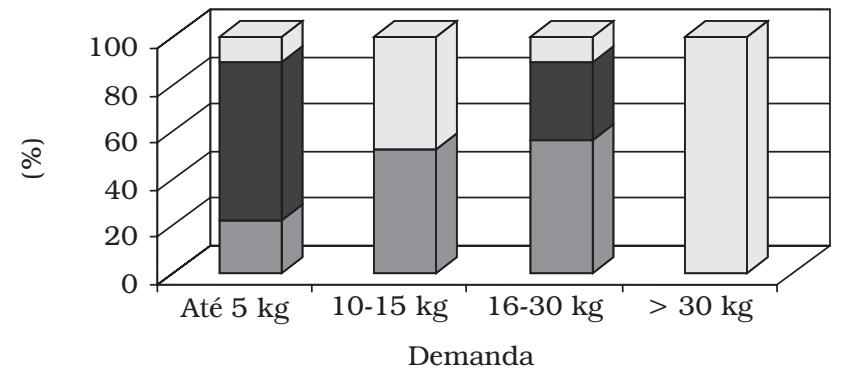

$\square$ Somente fresco $\square$ Congelado e fresco $\square$ Somente congelado

Figura 1. Demanda mensal das principais formas de aquisição dos mexilhões pelos comerciantes de Ubatuba - SP.
A demanda mensal por mexilhões nos estabelecimentos estudados nesta pesquisa e a forma de comercialização (pratos com mexilhão) apresentaram forte relação representada pelo elevado valor do $\mathrm{x}^{2}(64,4)$, obtido pela análise estatística. Os dados encontrados nas entrevistas mostraram-se altamente significativos $(p<0,0001)$.

Para os mexilhões adquiridos na forma congelada pelos estabelecimentos, $77,8 \%$ são provenientes, principalmente, de Santa Catarina e os demais $(22,2 \%)$, de Ubatuba.

Os estabelecimentos que trabalham com pratos mais elaborados mostraram preferência pelo produto congelado e sem concha, enquanto os quiosques dão preferência ao produto fresco, mas também, sem a concha, ou seja, subentende-se que estes optam pelo produto semicozido ou cozido, porém apenas resfriado.

A aquisição dos mexilhões sem a concha é igualmente requisitada por estabelecimentos de pouca e de alta demanda. Conclui-se assim que existe mercado para diversas formas de apresentação do produto, como apresentado na Figura 2. A compra de mexilhões na meia concha sempre esteve relacionada a estabelecimentos de maior demanda.

\section{Preferência na aquisição do produto-mexilhões pelo comerciante}

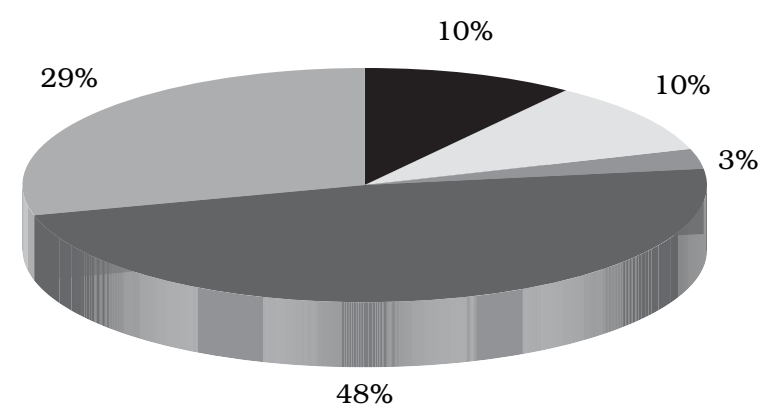

$\square$ Mariscado $\square$ 1/2 concha $\square$ Desmariscado
$\square$ Não comercializa $\square$ Não respondeu

Figura 2. Formas de aquisição dos mexilhões pelos comerciantes de Ubatuba - SP, quanto à presença das conchas.

Os dados de demanda pelos estabelecimentos e de origem dos mexilhões também apresentaram forte correlação $\left(x^{2}=55,8\right)$ e os dados são altamente significativos $(\mathrm{p}<0,0001)$.

Segundo os próprios comerciantes, os consumidores mostram preferência pelos mexilhões preparados à vinagrete (29\%), seguido pelo prato denominado caldeirada $(16,13 \%)$.

Um terço dos estabelecimentos adquire mexilhões frescos, sendo a totalidade na própria concha. Os mexilhões comercializados na meia concha são apresentados sempre na forma congelada, sendo que na comercialização de mexilhões congelados há predomínio do produto totalmente desconchado (40\%).

Segundo alguns donos dos quiosques entrevistados, o consumo local de mexilhões é limitado pela falta de rastre- 
abilidade, alto custo e ausência de conhecimento quanto ao preparo e armazenamento.

Para BARNI et al. ${ }^{6}$, apenas $29 \%$ da população graduada consome mexilhões em São Paulo e Porto Alegre e, cerca de $47 \%$, em Curitiba. Nesta pesquisa, também se pontuou um consumo mínimo entre os pós-graduandos e um baixo consumo entre pessoas com nível universitário, quando comparados às pessoas com nível escolar médio.

A maior parte dos entrevistados $(94,68 \%)$ consome mexilhões, mas $21,35 \%$ destes não os conheciam por este nome e sim por marisco. Uma das constatações mais relevantes da pesquisa de BARNI et al. ${ }^{6}$ diz respeito a este fato. Na capital de São Paulo, 18,47\% dos entrevistados não conhecem moluscos, o que representa uma população estimada de cinco milhões de pessoas ou 1250 mil famílias potenciais consumidoras que não conhecem o produto.

A familiaridade com o produto na presente pesquisa era esperada, visto tratar-se de uma localidade litorânea, onde se tem uma maior procura por produtos marinhos, bem como se esperava esse hábito alimentar voltado ao mar por parte da população local.

\section{Conclusões}

- Os mexilhões Perna perna constituem uma fonte protéica com baixo teor lipídico e calórico;

- Há variação dos constituintes químicos dos mexilhões Perna perna em função da sazonalidade, bem como do local de origem destes;

- Seguindo os padrões do RIISPOA para pescado, quanto a N-BVT e pH, os mexilhões apresentaram uma vida útil de 4 dias sob a temperatura de $10{ }^{\circ} \mathrm{C}(\mathrm{pl})$;

- Os mexilhões, 24 horas após as coletas, apresentaramse com qualidade satisfatória para consumo quanto aos quesitos físico-químicos aqui analisados;

- Há maior demanda local por mexilhões frescos e desmariscados, mas há mercado para diversas formas de apresentação do produto. $\mathrm{O}$ produto congelado tem grande aceitação por parte dos restaurantes e quiosques e estes preferem adquirir o produto já desconchado; e

- Existe um maior consumo de mexilhões por pessoas de nível médio e o prato preparado à base de mexilhões de maior demanda é o mexilhão à vinagrete.

\section{Agradecimentos}

À FAPESP - Fundação de Amparo à Pesquisa do Estado de São Paulo pelo apoio financeiro para o desenvolvimento desta pesquisa.

\section{Referências bibliográficas}

1. ACKMAN, R. G. Composición y valor nutritivo de los lípidios del pescado y del marisco. In: RUITER, A. El pescado y los productos derivados de la pesca: composición, propriedades nutritivas y estabilidad. Zaragoza: Acríbia, 1999. cap. 4, p. 81-121.
2. AMANAJÁS, C. C. Determinação dos compostos básicos totais de pescado e seu potencial para avaliação do frescor. 1985. 78 f.. Dissertação (Mestrado em Tecnologia de Alimentos) Faculdade de Engenharia de Alimentos e Agrícola, Universidade Estadual de Campinas, Campinas, 1985.

3. ANTONIOLli, M. A. Vida útil do mexilhão Perna perna (L.) processado e mantido sob refrigeração. 1999. 99 f.. Dissertação (Mestrado em Ciência dos Alimentos) - Departamento de Ciência e Tecnologia dos Alimentos, Centro de Ciências Agrárias, Universidade Federal de Santa Catarina, Florianópolis, 1999.

4. ASHIE, I. N. A.; SMITH, J. P.; SIMPSON, B. K. Spoilage and shelf-life extension of fresh fish and shellfish. Critical Reviews in Food Science and Nutrition, Amherst, v. 36, n. 1/2, p. 81-121, jan. 1996.

5. BARBETA, P. A. Estatística aplicada as ciências sociais. 2.ed. Florianópolis: UFSC, 1998. 283 p.

6. BARNI, E. J. et al. Estudo do mercado de mexilhões em São Paulo, Curitiba e Porto Alegre. 1. ed. Florianópolis: GMC/ EPAGRI, 2003. 43 p.

7. BATAlHA, M. O. et al. A maricultura no Estado de São Paulo. 1.ed. São Paulo: SEBRAE, 2002. 297 p.

8. Base de dados de nutrientes do USDA SR14. Mexilhão, azul, cozido. NDB $n^{\circ}$ 15165. Disponível em: <http://www.unifesp. br/dis/servicos/nutri/nutri.php?id=4336> . Acesso em; 04 Abril 2007.

9. BORGSTROM, G. Physicochemical methods. In: BORGSTROM, G. Fish as food. 1. ed. New York: Academic Press, 1965. v. 4, cap. 2, p.71-126.

10. BOTTA, J. R. Freshness quality of seafoods: a review. In: SHAHIDI, F.; BOTTA, J. R. Seafoods: chemistry, processing technology and quality. London: Chapman \& Hall, 1994. cap. 9, p. 140-167.

11. BRASIL. Decreto n. 30.691, de 29 de março de 1952. Alterado pelo decreto n. 1.255, de 25 de junho de 1962. Ministério da Agricultura, Departamento Nacional de Inspeção de Produtos de Origem Animal. Lex: Regulamento da Inspeção Industrial e Sanitária de Produtos de Origem Animal, Brasília, Publicado no Diário Oficial da União de 09 de novembro de 1973, n. 215, folha n. 11.443. 364 p.

12. BRASIL. Ministério da Agricultura, Pecuária e Abastecimento. Secretaria Nacional de Defesa Agropecuária. Laboratório Nacional de Referência Animal. Lex: Métodos analíticos oficiais físicoquímicos para controle de pescados e seus derivados, Brasília, cap. 11 , p. 5-6, 1981. Peixe fresco.

13. EU commission. Freshness, quality and safety in seafoods. Disponível em: <http://www.seafood.ucdavis.edu/pubs/ qualitysafety.doc > Acesso em: 16 Janeiro 2004.

14. GELLI, V. C. Aproveitamento de mexilhões: aspectos gerais Mollusca-Bivalvia. Fortaleza: LABOMAR, 1992. 64 p. (Monografia do curso de Especialização em Tecnologia de Produtos Pesqueiros, Departamento de Engenharia de Pesca, Universidade Federal do Ceará).

15. HUSS, H. H. Assurance of seafood quality. Rome: FAO, 1993. 169 p. (FAO Fisheries technical paper, 334)

16. HUNGERFORD, J. M. Fish and other marine products. In: ASSOCIATION OF OFFICIAL AGRICULTURAL CHEMISTS. Official methods of analysis. Washington, 1995. cap. 35, p. 1-30.

17. JAY, J.M. Microbiología moderna de los alimentos. 3. ed. Zaragoza: Acribia, 1994. 804 p. 
18. LATHAM, M. C. Macronutrientes: carbohidratos grasas, y proteínas. In: LATHAM, M. C. Nutrición humana en el mundo desarrollo. Roma: FAO, 2002. cap. 9, p. 101.

19. LIRA, G. M. et al. Fatty acids composition, chemical centesimal composition and caloric value in raw and boiled mollusks with coconut in the city of Maceió, Alagoas, Brasil. Revista Brasileira de Ciências Farmacêuticas, São Paulo, v. 40, n. 4, p. 1-11, out./ dez. 2004

20. LIUZZO, J. A. et al. A total reducing substance test for ascertaining oyster quality. Journal of Food Science, Chicago, v. 40, n. 1, p. 125-128, jan.1975.

21. LOMOVASKY, B. J.; MALANGA, G.; CALVO, J. Seasonal changes in biochemical composition of the clam, Eurhomalea exalbida (bivalvia: veneridae), from the beagle channel, Argentina. Journal of Shellfisheries Research, Canadá, v. 23, n. 1, p. 81-88, abril 2004.

22. Magalhães, A. R. M. Teor de proteína do mexilhão Perna perna (Linné, 1957) (Molusca - Bivalvia) em função do ciclo sexual. 1985. 117 f.. Dissertação (Mestrado em Ciências) - Instituto de Biociências, Universidade de São Paulo, São Paulo, 1985.

23. MARQUES, H. L. A. Criação comercial de mexilhões. 1. ed. São Paulo: Nobel, 1998. 109 p.

24. MATTAR, F. N. Pesquisa de marketing: metodologia, planejamento, execução e análise. 4. ed. São Paulo: Atlas, 1997. $225 \mathrm{p}$.

25. MENDEZ, M. H. M. Evolucão das bases voláteis totais e da trimetilamina em pescado e o seu uso como indicador de qualidade. 1974. 63 f.. Dissertação (Mestrado em Ciência dos Alimentos) - Faculdade de Ciências Farmacêuticas, Universidade de São Paulo, São Paulo, 1974.

26. MORGA, A. A. Avaliação do índice de frescor da pescada foguete (Macrodon ancylodon) conservada em gelo. 1975. 80 f.. Dissertação (Mestrado em Ciência dos Alimentos) - Faculdade de Tecnologia de Alimentos, Universidade Estadual de Campinas, Campinas, 1975.

27. NORT, E. Importância do controle físico na qualidade do pescado. In: SEMINÁRIO SOBRE CONTROLE DE QUALIDADE NA INDÚSTRIA DE PESCADO, 1., 1988, Santos. Anais... Seminário Sobre Controle de Qualidade na Indústria de Pescado. São Paulo: Instituto de Pesca, 1988. p. 135-144.
28. OGAWA, M.; MAIA, E. L. Manual da pesca: ciência e tecnologia do pescado. v. 1. São Paulo: Varela, 1999. 430 p.

29. RINALDI, F. D. et al. Produção, comercialização e perspectivas de expansão da atividade de cultivo de mexilhões Perna perna (L.) na região de Ubatuba, SP. In: SIMPÓSIO INTERNACIONAL DE INICIAÇÃO CIENTÍFICA DA UNIVERSIDADE DE SÃO PAULO, 11 ., 2003, Piracicaba. Anais do SIICUSP. São Paulo: Universidade de São Paulo, 2003. (compact disc)

30. RODRÍGUEZ-JÉREZ, J. J.; HERNÁNDEZ-HERRERO, M. M.; ROIG-SAGUÉS, A. X. New methods to determine fish freshness in research and industry. In: CIHEAM. Global quality assessment in Mediterranean aquaculture. Zaragoza: CIHEAM-IAMZ, 2000. v. 51, 149 p. Disponível em: <http://ressources.ciheam.org/util/ search/detail_numero.php?mot $=764 \&$ langue $=$ fr $>$ Acesso em: 15 Março 2004.

31. ROSA, R. C. C. et al. Manual de cultivo do mexilhão Perna perna. Florianópolis: EPAGRI, 1994. 140 p.

32. SCHRAMM, M. A. Caracterização e aproveitamento de mexilhões Perna perna (Linné, 1758). Rio Grande: FURG, 1993. 54 p. (Monografia do curso de graduação em Oceanologia). Faculdade de Oceanologia, Universidade Federal do Rio Grande.

33. TAVARES, M. et al. Métodos sensoriais, físicos e químicos para análise de pescado. In: SEMINÁRIO SOBRE CONTROLE DE QUALIDADE NA INDÚSTRIA DE PESCADO, 1., 1988, Santos. Anais do Seminário Sobre Controle de Qualidade na Indústria de Pescado. São Paulo: Instituto de Pesca, 1988. p.117-134.

34. WAKSMAN, S. A.; LOMANITZ, S. Contribution to the chemistry of decomposition of proteins and amino acids by various groups of microorganisms. Journal of Agricultural Research, Washington, v. 30, n. 3, p. 263-281, fev. 1925.

35. WESTLUND, L. Apparent historical consumption and future demand for fish and fishery products: exploratory calculations. In: KIOTO CONFERENCE OUTCOME \& PAPER PRESENTED, 1 ., 2002, Kioto. Papers presented. Rome: FAO Fisheries Department, 2003. Disponível em: <http://www.fao.org/DOCREP/006/AC442e/ AC442e13.htm > Acesso em: 04 Abril 2007.

36. WIEFELS, R. Marketing e mercado de pescados. In: CONGRESSO SEAFOOD EXPO, 1., 2004, São Paulo. Disponível em: <www. infopesca.org/articulos/18_El_pescado_y_su_marketing.pdf > Acesso em: 01 junho 2005. 